\title{
Association between Type 1 Modic Changes and Propionibacterium Acnes Infection in the Cervical Spine: An Observational Study
}

\author{
(D) M.M. Georgy, (D) F. Vaida, (D) M. Stern, and D. Murphy
}

\begin{abstract}
BACKGROUND AND PURPOSE: Research on the association between Propionibacterium acnes in the disc space and type 1 Modic changes in adjacent vertebrae is limited and has produced mixed results. The prevalence of bacteria in intervertebral discs contradicts the prior understanding that skeletal areas in the human anatomy are sterile; yet it opens new treatment possibilities. We investigated the relationship of $P$ acnes and type 1 Modic changes in the cervical spine.
\end{abstract}

MATERIALS AND METHODS: Over a 36-month period, we collected intraoperative biopsies of patients undergoing a routine cervical spine operation for degenerative disc diseases. The disc material was cultured aerobically and anaerobically for 7 days. All preoperative MR images were evaluated for Modic changes by a board-certified neuroradiologist. Medical records were reviewed for other spine interventions before the operation.

RESULTS: The study population consisted of 48 patients. Of these, 14 patients tested positive for $P$ acnes (29\%) at $\geq 1$ level. Additionally, 13 patients had type 1 Modic changes $(27 \%)$ at $\geq 1$ level; $54 \%$ ( $95 \% \mathrm{Cl}, 27 \%-84 \%)$ of patients who had type 1 Modic changes were also positive for $P$ acnes compared with $20 \%(95 \% \mathrm{Cl}, 7 \%-33 \%)$ of patients without type 1 Modic changes. The difference between these proportions was $34 \%(95 \% \mathrm{Cl}, 4 \%-64 \%)$. The Fisher exact test produced a $P$ value of .03 for the association between $P$ acnes and $M C l$, and .53 for the association between $P$ acnes and prior procedures.

CONCLUSIONS: We conclude that $P$ acnes was prevalent in the degenerated cervical spine and that type 1 Modic changes were predictive of a culture positive for $P$ acnes. We also found that the prevalence of $P$ acnes was not associated with previous interventions. If these results are validated by future studies, they could have a major impact on the standard of care for back and neck pain.

ABBREVIATION: $M C 1=$ type 1 Modic changes

D uring the past few years, several peer-reviewed publications concerning the correlation between type 1 Modic changes (MC1) on MR imaging and Propionibacterium acnes in the lumbar spine have produced polarized results. In 2013, Albert et $\mathrm{al}^{1}$

Received March 3, 2018; accepted after revision June 8.

From the Division of Biostatistics and Bioinformatics (M.M.G., F.V.), Department of Family Medicine and Public Health, University of California, San Diego, La Jolla, California; Joint Department of Medical Imaging (K.M.), University Health Network, Toronto, Ontario; and Southern California Institute of Neurological Surgery (M.M.G., M.S.), Escondido, California.

Paper previously presented at: Annual Meeting of the American Society of Neuroradiology and the Foundation of the ASNR Symposium, April 22-27, 2017, Long Beach California; American Society of Spine Radiology Annual Symposium, February 14-18, 2018, Scottsdale, Arizona; and Griboi Meeting, an Interdisciplinary Research Conference on Image-Guided Spine Therapy, Biomaterials and Interventional Implants, March 17, 2018, Los Angeles, California.

Please address correspondence to Mark Georgy, MD, University of California, San Diego, Department of Family Medicine and Public Health, Southern California Institute of Neurological Surgery, 705 East Ohio Ave, Escondido, CA 92025; e-mail: mgeorgy@ucsd.edu, markmgeorgy@gmail.com

http://dx.doi.org/10.3174/ajnr.A5741 performed a preoperative biopsy along with baseline and follow-up MR imaging for 61 patients planning to undergo a primary operation at a single level in the lumbar spine. Of the 61 patients, $43 \%$ had cultures positive for anaerobic bacteria, primarily $P$ acnes. Of these positive discs, $80 \%$ developed new Modic changes.

Shortly after, the same group published a double-blind randomized controlled trial investigating the efficacy of antibiotic treatment for patients with chronic low back pain and MC1. A total of 162 patients were randomized into 4 groups: Forty-five were given 1-dose antibiotics, 45 were given double-dose antibiotics, 36 were given a 1-dose placebo, and 36 were given a doubledose placebo. The antibiotics used were a combination of $500 \mathrm{mg}$ amoxicillin and $125 \mathrm{mg}$ clavulanate acid under the brand name Bioclavid. The primary outcome measure was the disease-specific Roland-Morris Disability Questionnaire, used for its ability to capture short-term changes in back pain. At 1-year follow-up, the mean Roland-Morris Disability Questionnaire score of the treat- 
ment group dropped to 7 from 15, while the mean score of the control group dropped to 14 from 15 . The differences in the scores produced a $P$ value $<.001$. Although a trend toward a doseresponse relationship was apparent, the relationship was not statistically significant. The authors concluded that Bioclavid could be considered a treatment option for a specific group of patients with chronic low back pain and $\mathrm{MC1} .^{2}$

In 2015 however, Rigal et $\mathrm{al}^{3}$ published a prospective study in which they took disc biopsies from 313 patients undergoing L4L5/L5-S1 fusion or disc prosthesis surgery. Arguing that a posterior approach has a high risk of contamination, they used an anterior retroperitoneal approach. They took intraoperative biopsies of 385 discs, 303 of which demonstrated MC1 on preoperative MR imaging. The biopsies were cultured for 4 weeks and subjected to histopathologic analysis. With $98.4 \%$ of all biopsies found sterile, only 6 cultures were positive, 2 of which were $P$ acnes and proposed as contamination. In addition, postoperative monitoring at 1 year did not indicate any infection. The authors concluded that no correlation existed between infection and disc degeneration. ${ }^{3}$

Despite the relative abundance of studies focused on the relation of $P$ acnes and $\mathrm{MC1}$ in the lower back, there are very few regarding the same topic in the neck. Hence, we took the initiative to develop an observational study of this relationship in the cervical spine.

\section{MATERIALS AND METHODS}

This was an observational study with approval from an institutional review board and run through a neurosurgery private practice operating in Tri-City and Palomar Medical Centers. During a 36-month period, 48 patients with 80 discs that were undergoing anterior/posterior cervical fusion, disc replacement, or discectomy were enrolled.

The study population comprised 24 women and 24 men, with an average age of 55 years and an age range of $18-87$ years. MR imaging protocol included T1- and T2-weighted sagittal, T2weighted axial, and gradient-echo axial imaging, and 40/48 patients also had STIR sagittal imaging. Patients underwent MR imaging, on average, 3 months before the procedure with a range of 1-10 months. All preoperative MR images were blindly evaluated for the presence, type, and levels of Modic changes by a board-certified neuroradiologist. In addition, discs were checked for narrowing, dissection, and bulges.

All biopsies were performed during open surgery with sterile pituitary rongeurs, and the cultures were carefully transported to the laboratory. The tissues were then ground and placed on a series of anaerobic and aerobic plates. The anaerobic plates used were the following: Brucella K1, Bacteroides Bile-Esculin, and Laked Blood with Kanamycin and Vancomycin. Aerobic incubation in $\mathrm{CO}_{2}$ was accomplished with the following plates manufactured by Becton Dickinson: Columbia Agar with 5\% Sheep Blood, Chocolate Agar, CNA Agar, and MacConkey Agar. Propionibacterium can take relatively longer to grow, so the cultures were incubated for up to 7 days.

Last, the medical records of all patients were checked for any interventions performed before enrollment, such as steroid injections or other operations. Sufficient information was
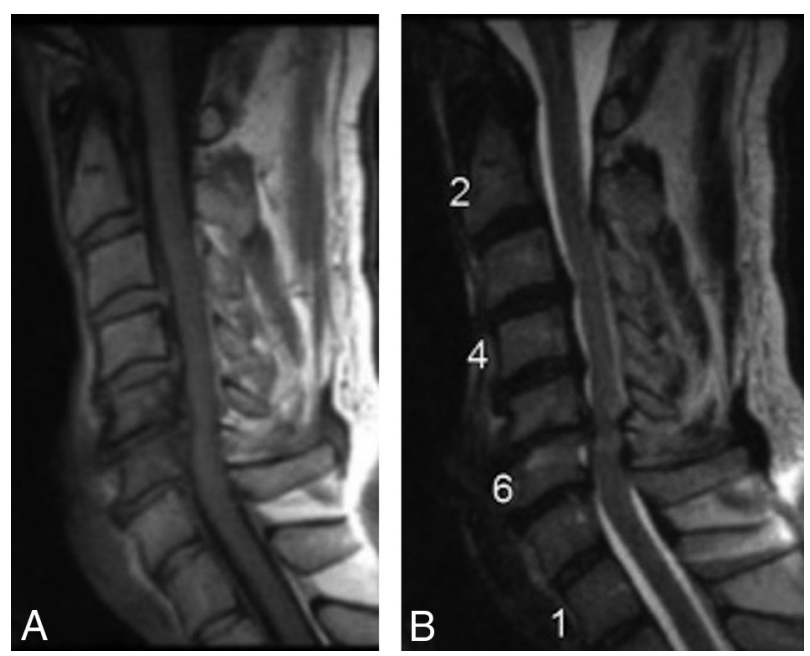

FIG 1. A 59-year-old male patient with neck pain who underwent discectomy at C5-C6 and was biopsy-positive for $P$ acnes. Preoperative sagittal MR imaging (T1- and T2-weighted) shows $\mathrm{MCl}$ and evidence of myelopathy at C5-C6.

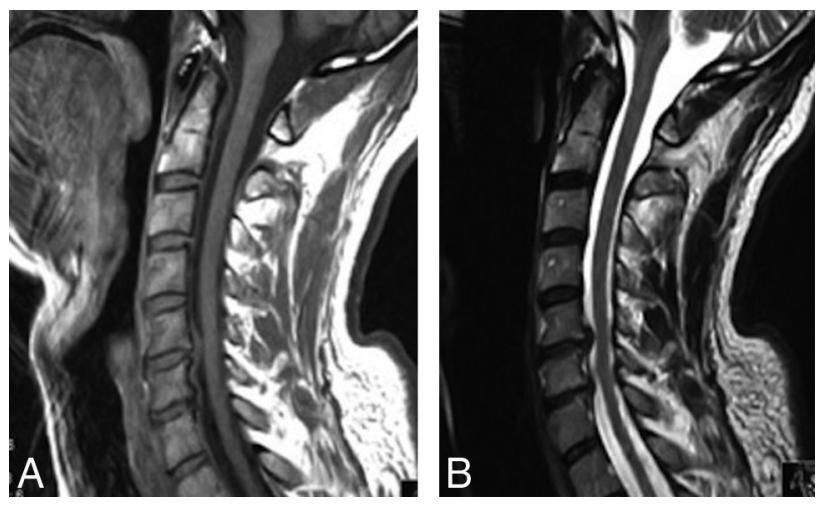

FIG 2. A 49-year-old male patient who underwent anterior fusion at C5-C6 and C6-C7 and was biopsy-positive for $P$ acnes at both levels. Preoperative sagittal MR imaging (T1- and T2-weighted) shows disc bulges at $\mathrm{C} 5-\mathrm{C} 6$ and $\mathrm{C} 6-\mathrm{C} 7$ with no evidence of $\mathrm{MCl}$.

found to confirm prior intervention status for 47 of the 48 enrolled patients.

SPSS Statistics, Version 24 (IBM, Armonk, New York) was used to record the data as well as perform the statistical analysis. All $P$ values reported in this article were generated with the Fisher exact test.

\section{RESULTS}

At the end of the study period, enrollment totaled 48 patients with 80 discs. The most common levels of the cervical spine that received treatment were the $\mathrm{C} 3-4, \mathrm{C} 4-5$, and $\mathrm{C} 5-6$ disc spaces. The types of operations each participant underwent were split as follows: Thirty-two had anterior fusion only, 9 had disc replacement only, 3 had anterior fusion and disc replacement, 3 had anterior and posterior fusion, and 1 had a discectomy.

Of the 48 patients, 14 were biopsy-positive for $P$ acnes (29\%) at $\geq 1$ level. In addition, 13 of the 48 patients had MC1 (27\%) at $\geq 1$ level (Figs 1 and 2). The remaining 35 patients had either type 2 Modic changes, mixed types, or none. Of the patients with MC1, 


\section{Fisher's exact test results}

\section{$P$ acnes and $\mathrm{MCl}$}

48 patients, 24 women and 24 men, average age of 55 years

14/48 patients had $P$ acnes

$13 / 48$ patients had $\mathrm{MCl}, 54 \%$ of which had $P$ acnes

(95\% Cl, 27\%-84\%)

$P$ value $=.03$

$54 \%$ were positive for $P$ acnes, compared with $20 \%$ of those without MC1; 16\% were positive for Staphylococcus epidermis, and these findings were considered a contamination. Patients with $\mathrm{MC} 1$ were significantly more likely to test positive for $P$ acnes than patients without MC1 $(P=.03)$ (Table). Thirty of the 47 patients with an accessible medical history had no intervention before study enrollment (64\%), while the remaining 17 had a spinal injection, an operation, or both. Participants with a prior procedure were no more likely than patients without a prior procedure to test positive for $P$ acnes $(P=.53)$. Therefore, the prevalence of $P$ acnes was unlikely to have been linked to contamination from prior procedures.

\section{DISCUSSION}

de Roos et $\mathrm{al}^{4}$ first identified bone marrow signaling changes in MR imaging of vertebrae adjacent to degenerative discs in 1987. These signal anomalies were attributed to degenerative disc disease rather than an infection or tumor. The following year, Modic et $\mathrm{al}^{5,6}$ formally classified the signaling changes into 3 types, and $\mathrm{MC1}$ is the most relevant to this study. Modic hypothesized that the signal intensity changes seen on MR imaging were not alone a causal pathologic process but rather a reflection of one, such as biomechanical stress or instability. ${ }^{7} \mathrm{He}$ found $\mathrm{MC} 1$ to be associated with disruption and fissuring of endplates and the formation of fibrovascular granulation tissue, which correspond to the inflammatory stage of degenerative disc disease and indicate an ongoing active process. ${ }^{5,6}$ Later research by Kjaer et $\mathrm{al}^{8}$ suggested that Modic changes constituted the crucial element in the degenerative process around the disc with regard to low back pain. They demonstrated that patients presenting with degenerative disc diseases and Modic changes together were more likely to have clinical symptoms than patients with degenerative disc diseases alone. Further, Toyone et $\mathrm{al}^{9}$ investigated the 3 types of Modic changes to determine whether 1 specific type was more strongly associated with low back pain than the others. They observed that $73 \%$ of patients with $\mathrm{MC} 1$ had low back pain, compared with $11 \%$ of patients with type 2 Modic changes.

$P$ acnes is an anaerobic, Gram-positive, rod-shaped bacterium that resides on the human skin, oral cavity, intestinal tract, and external ear canal as normal flora. ${ }^{10}$ In bone and joint infections, $P$ acnes is the most frequently isolated anaerobic microbe and has a strong correlation with vertebral osteomyelitis. ${ }^{11}$ Multiple recent publications have proposed that $P$ acnes is not only prevalent within spinal discs but may also play a pathogenic role in disc degeneration.

In this study, P acnes was isolated from 14/48 (29\%) cultures taken intraoperatively from the cervical spine. Similarly, Javanshir et $\mathrm{al}^{12}$ reported a prevalence of 9/25 (36\%) for $P$ acnes in disc material excised from the cervical spine. In the lumbar spine, at least 12 independent studies have reported a prevalence of $P$ acnes between $2 \%$ and $44 \% .^{13-15}$

Still, many authors have raised concerns that positive cultures are likely due to contamination. Their arguments include the following: biopsy needles may be exposed to skin flora, an anterior approach is considered more sterile, and contamination may have occurred during prior operations or injections. ${ }^{3,16}$ In this investigation, all biopsies were performed intraoperatively with an anterior approach, and no significant association was found between a prior procedure and the presence of $P$ acnes. Further, Lambert et $\mathrm{al}^{17}$ and Czaplewski ${ }^{18}$ challenged the findings of Rigal et $\mathrm{al}^{3}$ mentioned above, stating that $P$ acnes could not have been efficiently recovered because incubation was only performed in aerobic conditions. ${ }^{17,18}$

The other part of this study concerned the relationship between $P$ acnes in the disc space and MC1 in the adjacent vertebrae. We found that patients with $\mathrm{MC} 1$ were significantly more likely to produce a culture positive for $P$ acnes $(P=.03)$. This association could be indicative of pathogenic activity by $P$ acnes, though additional experiments, such as with an animal model, are required. Other investigators have hypothesized the mechanisms by which $P$ acnes may be instigating disc degeneration. In 2018, Yazhou et $\mathrm{al}^{19}$ published an article in Emerging Microbes \& Infections that demonstrated $P$ acnes promoting apoptosis of nucleus pulposus cells within an animal model. Also, Zamora et $\mathrm{al}^{20}$ found that injecting $P$ acnes into rat tail discs increased degeneration but did not result in new Modic changes.

This study has limitations. First, this was an observational study with a relatively small number of patients. Second, it lacked accurate reporting of patient pain scores and functional status before and after the operation. This information would have been useful to determine whether the presence of $P$ acnes in the disc had an association with increased pain reported by each patient. However, the primary goal was to investigate the prevalence of $P$ acnes in the cervical spine and its relationship with $\mathrm{MC} 1$, considering the uncertainty stemming from 2-sided evidence in the recent literature. Third, there was potential bias in MR imaging grading because 1 neuroradiologist read the images. Last, in comparison with most other publications involving the detection of $P$ acnes in the spine, this study did not include sophisticated methods such as polymerase chain reaction.

\section{CONCLUSIONS}

The volume of academic commentary surrounding the prevalence of $P$ acnes in the disc space of the spine and its possible pathogenicity has increased dramatically in recent years. If the findings of this article are replicated, there is the possibility of novel treatments for spinal pain. Therefore, the devotion of resources to further investigation in this area is justified.

Disclosures: Kieran Murphy-UNRELATED: Board Membership: IZI Medical Products, Active O, Comments: radiation therapy guidance systems and vertebroplasty devices, also ozone-generating devices; Patents (Planned, Pending or Issued): IZI Medical Products, Comments: I have 66 patents; Royalties: IZI Medical Products; Stock/Stock Options: Syunaptive Medlantis, CoraMed, Active O, Comments: I have invented devices that are the basis of multiple companies; Travel/Accommodations/Meeting Expenses Unrelated to Activities Listed: IZI Medical Products, Comments: for a hands-on training courses in spine intervention. 


\section{REFERENCES}

1. Albert HB, Lambert P, Rollason J, et al. Does nuclear tissue infected with bacteria following disc herniations lead to Modic changes in the adjacent vertebrae? Eur Spine J 2013;22:690-96 CrossRef Medline

2. Albert HB, Sorensen JS, Christensen BS, et al. Antibiotic treatment in patients with chronic low back pain and vertebral bone edema (Modic type 1 changes): a double-blind randomized clinical controlled trial of efficacy. Eur Spine J 2013;22:697-707 CrossRef Medline

3. Rigal J, Thelen T, Byrne F, et al. Prospective study using anterior approach did not show association between Modic 1 changes and low grade infection in lumbar spine. Eur Spine J 2016;25:1000-05 CrossRef Medline

4. de Roos A, Kressel H, Spritzer C, et al. MR imaging of marrow changes adjacent to end plates in degenerative lumbar disk disease. AJR Am J Roentgenol 1987;149:531-34 CrossRef Medline

5. Modic MT, Steinberg PM, Ross JS, et al. Degenerative disk disease: assessment of changes in vertebral body marrow with MR imaging. Radiology 1988;166(1 Pt 1):193-99 CrossRef Medline

6. Modic MT, Masaryk TJ, Ross JS, et al. Imaging of degenerative disk disease. Radiology 1988;168:177-86

7. Modic MT. Modic type 1 and type 2 changes. J Neurosurg Spine 2007; 6:150-51; discussion 151 CrossRef Medline

8. Kjaer P, Korsholm L, Bendix T, et al. Modic changes and their associations with clinical findings. Eur Spine J 2006;15:1312-19 CrossRef Medline

9. Toyone $\mathrm{T}$, Takahashi $\mathrm{K}$, Kitahara $\mathrm{H}$, et al. Vertebral bone-marrow changes in degenerative lumbar disc disease: an MRI study of $\mathbf{7 4}$ patients with low back pain. J Bone Joint Surg Br 1994;76:757-64 Medline

10. Perry A, Lambert P. Propionibacterium acnes: infection beyond the skin. Expert Rev Anti Infect Ther 2011;9:1149-56 CrossRef Medline

11. Walter G, Vernier M, Pinelli PO, et al. Bone and joint infections due to anaerobic bacteria: an analysis of 61 cases and review of the literature. Eur J Clin Microbiol Infect Dis 2014;33:1355-64 CrossRef Medline
12. Javanshir N, Salehpour F, Aghazadeh J, et al. The distribution of infection with Propionibacterium acnes is equal in patients with cervical and lumbar disc herniation. Eur Spine J 2017;26:3135-40 CrossRef Medline

13. Agarwal V, Golish SR, Alamin TF. Bacteriologic culture of excised intervertebral disc from immunocompetent patients undergoing single level primary lumbar microdiscectomy. J Spinal Disord Tech 2011;24:397-400 CrossRef Medline

14. Stirling A, Worthington T, Rafiq M, et al. Association between sciatica and Propionibacterium acnes. Lancet 2001;357:2024-25 CrossRef Medline

15. Wedderkopp N, Thomsen K, Manniche C, et al. No evidence for presence of bacteria in Modic type I changes. Acta Radiol 2009;50: 65-70 CrossRef Medline

16. Georgy M, Stern M, Murphy K. What is the role of the bacterium Propionibacterium acnes in type 1 Modic changes? A review of the literature. Can Assoc Radiol J 2017;68:419-24 CrossRef Medline

17. Lambert $P$, Elliott $T$, Worthington $T$, et al. Letter to the Editor concerning "Prospective study using anterior approach did not show association between Modic 1 changes and low grade infection in lumbar spine" by Rigal J, et al. Eur Spine J 2016;25: Apr; 25(4): 1000-05. Eur Spine J 2016;25:3377-78 CrossRef Medline

18. Czaplewski LG. Letter to the Editor concerning "Prospective study using anterior approach did not show association between Modic 1 changes and low-grade infection in lumbar spine" by Rigal $\mathrm{J}$, Thelen T, Byrne F, Cogniet A, Boissière L, Aunoble S, Le Huec JC (Eur Spine J [2016]; 25(4):1000-05. doi: 10.1007/s00586-016-43965). Eur Spine J 2016;25:3379-80 CrossRef Medline

19. Lin $Y$, Jiao $Y$, Yuan $Y$, et al. Propionibacterium acnes induces intervertebral disc degeneration by promoting nucleus pulposus cell apoptosis via the TLR2/JNK/mitochondrial-mediated pathway. Emerg Microbes Infect 2018;7:1 CrossRef Medline

20. Zamora T, Palma J, Andia M, et al. Effect of Propionibacterium acnes (PA) injection on intervertebral disc degeneration in a rat model: does it mimic Modic changes? Orthop Traumatol Surg Res 2017;103:795-99 CrossRef Medline 